\title{
Video media as an assessment tool in psychology
}

Sandra Rankin and Rob Willson

\section{University of Greenwich, School of Health \& Social Care}

Poster presentations have not changed much over time and have in many cases become a very static classroom activity. We decided to approach the topic in a different way, building on the technology currently available. By involving students in a new type of poster activity using video and YouTube as part of their course assessment, we wanted to put the fun back into learning and make it more engaging for students.

Making short videos was introduced onto a generic skills and personal development course which encourages students to engage in a variety of activities to help them develop their skills and recognise their own strengths and weaknesses. Approximately 125 first year undergraduate students were enrolled onto a psychology course, where students are predominately aged between 18-25 years and $80 \%$ female.

Psychology as a subject already demands a certain amount of computer literacy from students as it uses IT and computers in a number of ways. Therefore exposure to new experiences of ICT and emerging technologies have been shown to be benefi cial to students, both in enhancing their own skills and helping to understand subject knowledge (Clay, 2009; HEFCE, 2009). Face-to-face time is very limited in classrooms (especially with large numbers) and current technologies allow students to engage with each other (and with tutors) outside of the classroom more than ever before. The flexibility offered by technology allows learning to be expanded in ways that can extend and open up the classroom to the world beyond it. Students are no longer restricted to learning by the classroom clock and, equally important, tutors are no longer restricted by the same constraints.

New learning technologies have meant that students, as well as staff, need to engage in new ways of teaching to stimulate learning. Firstly, many students are more aware of technology and how to manipulate it. Many students are able to manage several media streams and channels of electronic communication at the same time (Whitehouse, 2009). Students routinely engage in several forms of communication, including the virtual learning environment (VLE), social networks, texting, webcams, vodcasts, private messaging 
and mobile phones. For those that do not, the reasons are generally due to a lack of opportunity or exposure to a particular technology rather than an unwillingness to engage (Attewell, 2005).

We wanted an activity that provided students with the scope to be creative, as well as providing opportunities for new learning. Producing video posters seemed to offer this possibility and also fitted in well with the general ethos of the course. Students were advised that a selection of the best would be uploaded to the Departmental YouTube channel. We had a view that this would be something that students would subscribe to and that it would enhance discourse on other platforms, such as social network sites (e.g. Facebook). The idea was to stimulate discussion about the work created. However, groundwork needed to be established prior to full implementation.

\section{Pilot activity}

We identified several implications that needed to be considered when changing this activity from a simple paper and pencil task to a more elaborate video version of a poster. We attempted to introduce this activity into seminars just to see how receptive the students were to the idea of making a video instead of drawing a poster. Students were allocated into groups within their seminars and were provided with a WebCT chat room for group discussions. A detailed task sheet with deadlines was provided, so that students had a time frame in which to work and a checklist of the various implementation stages they needed to achieve to successfully complete their videos (see Appendix A).

Several challenges were immediately apparent at the start of the task. Students were initially expected to work individually in class, engaging with different online reaction time studies. This provided some background information and first-hand experience of what the studies entailed. Students found this enjoyable and engaged with the task. However, when the students were then asked to contact each other to begin collaboration on making a short video of their own, this was not so well received. Comments such as 'Are we going to be assessed?', 'How much is it worth on the course?' were the immediate responses. Some students took the initiative and emailed others in their group to arrange meetings. However, if there was no response, students took no further action. It seemed students were unwilling to engage with other students whom they did not know personally, or alternatively they thought that the tutors should organise communication within groups. It would seem that we overestimated students' willingness to engage in any activity that was perceived as time consuming, that required a degree of persistence, and possibly most importantly, that was not formally assessed. We did observe that a few groups managed to agree on what to film as the basis for a study but very few groups completed the activity through to the finish. 


\section{Reshaping the activity}

As a learning concept that engaged students in understanding the principles of investigating psychology and, equally important, developed the students' own personal skills of communication, cooperation and time management, we thought the activity was worth pursuing with a few amendments for the following academic year. Firstly, the activity became a graded assessment and therefore the whole process of engagement by the students was different. Additionally, more guidelines were provided, which broke the task down into four parts, making the process more transparent. The sections of the task were individual activity, group engagement, video proposal submission and video production.

Further details about the students' responsibilities (learning and management) and tutor responsibilities (teaching and management) were provided and two forms of formative quizzes were designed to further engage and develop the students' understanding of the task requirements. A checklist and group chat rooms, with contact information, were set up so students could initiate contact with each other.

Introducing a proposal submission served two distinct purposes. First, students had to consider in advance how to design the study they were going to fi Im and consider practical as well as ethical issues about filming. Second, the proposal provided an opportunity for the tutors to review the proposal and provide formative feedback.

\section{Technical expertise}

No expertise was required from any student beyond having a mobile phone with a video facility. Students were also allowed to use their own video cameras or camcorders. Departmental equipment was made available on a first come, first served basis. Students were encouraged to use mobile phones for convenience and to emphasise the simplicity of the video required. Very little expertise was needed from tutors as much of the technology was low level. However, it could potentially become a resource issue as more grading is required by tutors. New marking criteria also needed to be developed to give summative feedback to students on the final video.

At the time of writing, students have not yet fully completed the revised activity and until then we cannot gather quantitative or any qualitative data on the students' perceptions of the activity. We have a task evaluation sheet that students will be asked to complete, which will rate the activity on a range of issues such as enjoyment, complexity, communication, perception of skills used and/or gained (time management, communication, teamwork, decision making/problem solving, etc).

Watch this space! 
Compass: The Journal of Learning and Teaching at the University of Greenwich, Issue 3, 2011

\section{References}

Attewell, J. (2005) Mobile Technologies and Learning. The M-Learning Project. The Learning and Skills Development Agency. London.

Becta (2008) Harnessing Technology: Next Generation Learning 2008-14. Available at).

http://webarchive.nationalarchives.gov.uk/20101102103654/publications.becta.org.uk//display.cfm?r esID=37346.

Clay, J. (2009) The future of Learning is mobile Presentation. JISC Online E-Learning Conference 2009.

The Higher Education Funding Council, (2009) Enhancing learning and teaching through the use of technology: a revised approach to HEFCE's strategy for e-learning. Available at: www.hefce.ac.uk/pubs/hefce/2009/09_12/09_12.pdf (Accessed December, 2009).

Whitehouse, R. (2009) Reluctant Technologist. http://elearningstuff.wordpress.com.

Appendix A: Video poster task checklist

\begin{tabular}{|l|l|l|}
\hline \multicolumn{3}{|l|}{ Groupwork - Video Poster Task Checklist } \\
\hline & Check List & Yes/No \\
\hline $\mathbf{1}$ & Online Reaction Time Test - noted average & \\
\hline $\mathbf{2}$ & Bullet Test - noted average & \\
\hline $\mathbf{3}$ & Zapper Test - noted average & \\
\hline $\mathbf{4}$ & Sheep Test - noted average & \\
\hline $\mathbf{5}$ & Checked list for group members & \\
\hline $\mathbf{6}$ & Checked chat group works & \\
\hline $\mathbf{7}$ & Checked group e-mails work & \\
\hline $\mathbf{8}$ & Checked for best meeting times online & \\
\hline $\mathbf{9}$ & Checked for best meeting times f2f & \\
\hline $\mathbf{1 0}$ & Discussed literature reviewing strategy & \\
\hline $\mathbf{1 1}$ & Checked video demo is viewable & \\
\hline $\mathbf{1 2}$ & Checked 'My Video exercise 'completed & \\
\hline $\mathbf{1 3}$ & Checked 'How much do you know' quiz completed & \\
\hline $\mathbf{1 4}$ & Checked video proposal due date & \\
\hline
\end{tabular}

You can use this if you wish to check your progress individually or as a group 